\title{
Environmental reduplication associated with right frontal and parietal lobe injury
}

\author{
R OBERT L R UFF A N D B R UCE T VOLPE \\ From the Department of Neurology, The New York Hospital, Cornell Medical Center, New York
}

SUMMARY Four patients with environmental reduplication, a specific form of spatial disorientation and confabulation are described. The patients maintained that their hospital rooms were located in their homes. Each patient had evidence of right frontal or right parietal injury based upon computed tomography, neurosurgery, and neuropsychological testing. The factors associated with environmental reduplication were: impaired spatial perception and visual memory, inability of the patients to recognise the inconsistency between their believed location and their actual location, confusion soon after admission to hospital, and a strong desire to be at home.

Environmental reduplication (ER) is a modalityspecific form of reduplicative paramnesia. In this disorder of spatial orientation the patients insist that an unfamiliar environment, such as a hospital room is located in or near a place important to them, such as their homes. ${ }^{1-7}$ ER may be present with other forms of orientation impairment, ${ }^{14}{ }^{4}$ or it may exist as an isolated cognitive deficit. ${ }^{237}$ In the latter cases, the patients knew that they were in a hospital, and could usually indicate its correct location. However, they confabulated that the hospital or a branch of the hospital had been relocated closer to or in their homes.

The necessary conditions to produce environmental reduplications have not been clearly established. Benson et al ${ }^{\tau}$ state that this condition requires that the patients cannot recognise the inconsistencies between their believed locations and contradictory environmental cues. Alternatively Weinstein and associates ${ }^{589}$ maintain that reduplicative phenomena are psychological mechanisms for coping with the stress of brain injury and that multiple patterns of reduplication were governed by the type of neurological disorder present. Of the 25 reported cases of environmental reduplication, only five patients had detailed neuropsychological testing ${ }^{3}$ and specific neuropathological correlations were not available for

Address for reprint requests: Dr RL Ruff, Division of Neurology, RG-20, University of Washington School of Medicine, Seattle,
WA 98195.

Accepted 20 November 1980 any of these cases. This report describes four additional patients with environmental reduplication, their associated cognitive and neurological impairments, and localisation of the underlying neuropathology by computed tomography (CT), and neurosurgery.

\section{Methods}

The four patients studied were admitted to the Neurology Services of The New York Hospital-Cornell Medical Center or Memorial-Sloan Kettering Hospital between 1977 and 1979. Their evaluations included CT and neuropsychological testing including: Weschler Adult Intelligence Scale (Wais), ${ }^{10}$ Weschler Memory Scale, ${ }^{11}$ Benton Visual Retention Test, ${ }^{12}$ picture drawing ability, Wisconsin Card Sorting, ${ }^{13}$ and kinesthetic apraxia. ${ }^{14}$ Neuropsychological testing was performed during the period when the patients displayed environmental reduplication, and after they recovered.

\section{Case reports}

Case 1 This 64 year old right handed woman was transferred from an outside hospital for treatment of a right parietal tumour. One month earlier her family had noted that she was becoming short-tempered and was having difficulty finding her way around town. A day before her admission she fell and became drowsy. The patient was treated with steroids and then transferred to Memorial-Sloan Kettering Hospital. At Memorial Hospital, the patient had left hemiparesis and left inferior quadrantanopia, with leftsided visual and sensory extinction to deable simul- 
taneous stimulation (DSS). She was awake, alert, and without aphasia or agnosia. She was oriented to person and time, but when asked her location she insisted that she was at home. CT scan demonstrated a right parietal tumour with oedema extending into the right frontal lobe.

The patient lived in a small seacoast town 500 miles from New York City. She recalled the events of the prior day and stated that she had travelled to Memorial Hospital and then returned to her home where her "doctors had constructed a duplicate Memorial Hospital". When asked to look out the window and point out her town's landmarks she stated that the new buildings associated with the second Memorial Hospital obscured the familiar view of her town. She admitted that it was implausible for her to have travelled roundtrip from her home to New York City or for a hospital to have been constructed so quickly. Nevertheless, she continued to insist that she was at home. When the patient was told that she should have an operation, she stated that she would travel back to New York City because "they have better surgeons at the other Memorial Hospital." That evening the patient believed that she had taken a bus trip back to New York City. At operation, a glioblastoma multiforme was partially resected from the right parietal lobe. After operation, the patient was treated with whole brain radiation therapy and steroids. Later the patient still maintained that she was at home: "You all tell me that I am in Sloan-Kettering Hospital in New York City but I know that I am home".

Table Neuropsychological test result

\begin{tabular}{|c|c|c|c|c|}
\hline \multirow[t]{2}{*}{$\begin{array}{l}\text { Psychological test } \\
\text { (expested normal values) }\end{array}$} & \multicolumn{4}{|c|}{$\begin{array}{l}\text { Patient (result during } E R / \\
\text { result during recovery) }\end{array}$} \\
\hline & 1 & 2 & 3 & 4 \\
\hline $\begin{array}{l}\text { WAIS } \\
\text { Verbal (100) } \\
\text { Performance (100) }\end{array}$ & $\begin{array}{r}115 /- \\
80 /-\end{array}$ & - & $\begin{array}{r}110 / 115 \\
76 / 105\end{array}$ & $\begin{array}{l}80 / 100 \\
56 / 96\end{array}$ \\
\hline $\begin{array}{l}\text { Modified Weschler memory s } \\
\text { Semantic }\end{array}$ & & & & \\
\hline $\begin{array}{l}\text { short term }(23 \cdot 1 \pm 6 \cdot 1 \\
\frac{1}{2} \text { hour }(20 \cdot 8 \pm 6 \cdot 4)\end{array}$ & $\begin{array}{l}24 / 22 \\
21 / 20\end{array}$ & $\begin{array}{l}24 / 24 \\
22 / 23\end{array}$ & $\begin{array}{l}23 / 24 \\
21 / 22\end{array}$ & $\begin{array}{l}15 / 22 \\
11 / 20\end{array}$ \\
\hline $\begin{array}{l}\text { Figural } \\
\text { short term }(10 \cdot 4 \pm 2 \cdot 7) \\
\frac{1}{2} \text { hour }(9 \cdot 1 \pm 2 \cdot 9)\end{array}$ & $\begin{array}{l}5 / 8 \\
4 / 7\end{array}$ & $\begin{array}{l}5 / 11 \\
3 / 9\end{array}$ & $\begin{array}{l}4 / 10 \\
3 / 8\end{array}$ & $\begin{array}{l}1 / 8 \\
0 / 7\end{array}$ \\
\hline $\begin{array}{l}\text { Benton visua! retention test } \\
\text { number correct }(\geqslant 8)\end{array}$ & $2 / 6$ & $3 / 8$ & $3 / 9$ & $1 / 8$ \\
\hline $\begin{array}{l}\text { Wisconsin card sorting } \\
\text { categories completed }(\geqslant 4)\end{array}$ & $1 / 4$ & - & $2 / 6$ & $0 / 5$ \\
\hline $\begin{array}{l}\text { Kinesthetic apraxia } \\
\text { (present/absent) }\end{array}$ & $\mathbf{P} / \mathbf{A}$ & $\mathbf{P} / \mathbf{A}$ & $\mathbf{P} / \mathbf{A}$ & $\mathbf{P} / \mathbf{A}$ \\
\hline
\end{tabular}

Psychological testing indicated that the patient had impaired spatial perception and visual memory (table). Her low WAIS performance scores resulted from particular difficulty with picture completion and arrangement, block design and object assembly. When asked to copy a picture, she would accurately draw individual details but she could not incorporate these details into a unified picture. She could not draw a floor plan of her room and she distorted the distances between cities when she drew a map of the northeast United States. She was able, however, to describe accurately the direction and the particular routes one would take travelling from Maine to New York City. Although she could not recall any of three geometric shapes after three minutes, she had no difficulty with verbal memory. The patient had kinesthetic apraxia, ${ }^{14}$ and perseverated after only one category change on the Wisconsin Card Sorting Test. ${ }^{8}$

One month after operation, her cognitive deficits had improved (table) and the patient began to question whether she was really at home. She had difficulty explaining her prior environmental reduplication, but stated that she was uncomfortable in the hospital and would rather have been at home. The patient died two months later of recurrent tumour, without recurrence of environmental reduplication.

Case 2 A 23 year old right handed woman was admitted to the New York Hospital with sudden onset of headache, apathy, left sided hemiparesis and sensory extinction to double simultaneous stimulation. CT revealed a right frontoparietal haematoma, and arteriography demonstrated an arteriovenous malformation (AVM) of the prerolandic branch of the right middle cerebral artery. The haematoma and AVM were resected. At operation, the cerebrospinal fluid was clear. After operation, the patient was awake with a slight left hemiparesis and sensory extinction to double simultaneous stimulation. The patient was oriented to person and time, but stated that she was at home. When told that she was in the New York Hospital, the patient looked around her hospital room, smiled, and stated how kind it was for the New York Hospital to have constructed an annexe in her home.

Psychological testing suggested that the patient had impaired spatial perception and visual memory (table). The patient was unable to draw a floor plan of her room or a map of New York City or the United States; however, she could describe the correct route to get from one part of the city to another. She could not accurately copy geometric forms or correctly complete partially drawn capital letters. ${ }^{15}$ In drawing a picture, she would draw individual parts correctly but could not join the parts into a unified whole. Her digit span and ability to remember words or stories was normal, but she could only recall one of three geometric shapes after three minutes. One week after operation, the patient's spatial perception and visual memory had improved (table) and she began to question her belief that she was at home. Ten days after operation the patient stated that she was in the "real" New York Hospital. At this point, she said that she had been confused when she awoke after operation and had wished that she were at home.

Case 3 This 29 year old right handed male was admitted to the New York Hospital for evaluation of a three month history of right frontal headache and two 
weeks of progressive left hand clumsiness. CT demonstrated a right posterior frontal meningioma. Before her operation, the patient had no cognitive impairment. Operation 24 hours after admission, was complicated by intraoperative haemorrhage. CT later indicated a posterior right frontal lobe haematoma extending into the anterior right parietal lobe. The patient was confused the first day after operation. He was disoriented in time. He knew that he was in a hospital in Manhattan, but he could not remember its name. By the second day after operation, the patient was awake and alert with a moderate left-sided hemiparesis and sensory extinction to double simultaneous stimulation, but no anosognosia. He was oriented to time and person. When asked his location, he stated that he was at home in a branch of the New York Hospital. The patient said that this branch hospital was built in the bedroom of his home, and that he had been transported there by helicopter after surgery.

Psychological testing indicated impaired spatial perception and visual memory (table). The low WAIS performance IQ reflected the patient's difficulty with picture arrangement and completion, block design and object assembly. He could not copy three dimensional geometric figures, and when he tried to copy a picture, he drew the individual parts of the picture out of proportion to each other. He could not draw a map of New York City or the United States, but he could describe how to get from one part of the city or the United States to another. His verbal memory was normal but he did poorly on visual memory tests. He perseverated after two category changes on the Wisconsin Card Sorting Test. ${ }^{13}$ By the third week after operation, the patient's motor, sensory, and cognitive impairments began to improve (table), and the patient started to question his earlier perception of a second New York Hospital being constructed in his home. One month after surgery, the patient stated that he no longer believed that he was at home or that there was another New York Hospital in his home. The patient stated that his initial misconception about his location might have resulted from his preoperative anxiety and desire to go home immediately after surgery.

Case 4 This 60 year old woman was brought to the New York Hospital with a three day history of progressive drowsiness and right frontal headache following blunt trauma to the head without loss of consciousness. On admission, the patient was apathetic with a left hemiparesis. CT scan showed a right frontal subdural haematoma which was evacuated. After two days of confusion she was awake and alert with minimal left sided weakness and sensory extinction to double simultaneous stimulation. She claimed that she was at home and stated that it was very convenient to have the New York Hospital in her home. She believed that the patient in the bed to her left was actually her husband. She stated that her husband would allow the neighbouring patient to stay in the bed while her husband visited her, but after visiting hours, her husband would chase the other patient away so that her husband could stay next to her. The patient was pleased that her "husband" in the next bed no longer snored. Though she knew the date correctly, the patient could not accurately gauge elapsed time so that she frequently did not know what time of the day it was. Misconstruction of her surrounding persisted despite repeated attempts by her family to convince her that she was not at home. The patient had general memory impairment as well as spatial perception and visual memory deficits (table). She had a digit span of only four numbers forward, and her arithmetic ability was poor. Her low WAIS performance score reflected extremely poor scores in picture completion and arrangement, block design, and object assembly. Her visual memory was impaired to a greater extent than was her verbal memory. In attempting to draw a floor plan of her room she ignored several of the features on her left. She could not describe how to get from one part of her room to another, or how to travel between different points in New York City. When she attempted to copy a picture, she would copy individual parts but could not produce a complete drawing.

During the first month after operation, the patient's cognitive function returned to normal (table). She stated that the patient in the bed next to her was not her husband and that she was in the New York Hospital, not at home. The patient indicated that her recent confusion may have resulted from her difficulty in accepting that she was not at home. She said that during the past 40 years she had never before been separated from her husband nor stayed away from home for more than a day.

\section{Discussion}

Environmental reduplication is an unusual disorder of spatial orientation. In the majority of the earlier cases, it was associated with multiple reduplicative phenomena.4589 Those patients, however, had lesions which generally produced widespread cerebral disorder, as suggested by diffusely abnormal electroencephalograms. ${ }^{4} 589$ There are six cases in which environmental reduplication occurred as a relatively focal disorder. ${ }^{2} 37$ Benton et $a l^{7}$ suggested that these patients suffered from combined frontal lobe and right hemisphere dysfunction, but there was no neuropathological confirmation of this.

Three of our four patients displayed environmental reduplication as a specific disorder of orientation and had right parietal or frontal lobe injury shown by CT. In addition to environmental reduplication, patient 4 stated that the neighbouring patient was her husband and she could not judge elapsed time. This patient had a traumatic right frontal subdural haematoma and probably suffered from more widespread cerebral injury 
than our other patients. Psychological testing indicated that patient 4 had more severe cognitive disorder than our other patients. These observations suggest that environmental reduplication may occur as a specific disorder of orientation when there is focal right frontal and parietal lobe injury, whereas more diffuse cerebral injury is associated with more widespread disorientation.

The specific cognitive deficits in our patients were compatible with the CT localisation of their cerebral injuries. Both clinical ${ }^{15-19}$ and experimental ${ }^{16} 15-22$ data suggest that the right parietal lobe is important in visual-spatial perception. Patients with parietal lobe lesions have difficulty recognising objects in different perspectives, and generally cannot trace routes or draw maps. ${ }^{23-25}$ However they generally do not have difficulty describing routes or familiar scenes. Disorders of the latter type more often accompany general memory problems. ${ }^{19}$ In patients with frontal lobe damage inability to reconcile conflicting data, ${ }^{14}$ kinesthetic apraxia, ${ }^{14}$ and poor performance on the Wisconsin Card Sorting Test $^{13}$ are characteristic findings.

The pattern of spatial disorientation without temporal disorientation, in patients 1 to 3 is not a general characteristic of confused patients. Although isolated temporal disorientation is common in confusional states ${ }^{26-28}$ isolated spatial disorientation ${ }^{27}$ suggests either right sided or bilateral parietal injury. ${ }^{15-19}$ Confused patients usually have temporal disorientation before they develop spatial disorientation. ${ }^{27-2 s}$ Our own experience also indicates that spatial disorientation without temporal disorientation is uncommon in confusional states due to trauma or toxic-metabolic encephalopathy. Among 180 confused patients, every patient was disoriented in time, but only 50 patients were additionally disoriented in place. In those patients with both disorders, disorientation in time preceded disorientation to place, and took longer to resolve.

The behavioural features common to our patients and those in the literature ${ }^{3}{ }^{7}$ were investigated further with neuropsychological techniques (table). The results suggest that environmental reduplication was associated with impaired spatial perception and visual memory. Characteristically, patients could not incorporate parts of a picture into an integrated whole, and they drew distorted maps. They had impaired visual memory. However, patients 1 to 3 did not have widespread cognitive impairment. Their verbal memories were normal, and the WAIS verbal IQ was normal in the two patients tested. When confronted with the physical contradiction of their supposed spatial location, all of our patients told a detailed story about their environmental duplication and displacement; however, with the exception of patient 4 , they did not confabulate about other aspects of their identity or condition. The parallel between the recovery from cognitive deficits and the resolution of environmental reduplication in our patients suggests an association between the two.

In addition to the specific cognitive defects of impaired spatial perception and visual memory, all our patients were confused or apathetic early in their hospital course. Benson et al ${ }^{\tau}$ have suggested that patients arriving at the hospital in a confused state have persistent spatial orienting difficulties. In our patients it is possible that their initial confusion combined with their focal cognitive impairment may have led to their isolated spatial disorientation. Other factors may have contributed to the specificity of their disorientation, that is that all our patients insisted that they were at home. When they recovered each claimed that their confabulated stories resulted from a desire to be at home. Though it is difficult to know how this desire may have contributed to the formation of environmental reduplication in our patients, others $5 ;$ " have suggested that motivation may be essential in the formation and pattern of reduplication.

In summary, environmental reduplication in each of our patients was associated with a right parietal or frontal cerebral lesion, impaired spatial perception and visual memory, confusion or apathy early in the hospital course, and a strong desire to be at home.

This work was partially supported by a NINCDS Teacher-Investigator Award NS 00498 to Dr Ruff.

\section{References}

1 Pick A. Clinical studies III. On reduplicative paramnesia. Brain 1903; 26:260-7.

2 Head H. A phasia and Kindred Disorders. London: Cambridge University Press, 1926; 493-4.

3 Paterson A, Zangwill OL. Recovery of spatial orientation in the posttraumatic confusional state. Brain 1944; 67:54-68.

4 Bender MB, Furlow LT, Teuber HL. Alterations in behavior after massive cerebral trauma (intraventricular foreign body). Confinia Neurol 1949; 9:140-54.

5 Weinstein EA, Kahn RL, Sugarman LA. Phenomenon of reduplication. Arch Neurol Psychiatry 1952; 67:808-14.

6 Levin M. Delirium: an experience and some reflections. Am J Psychiatry 1968; 124:1120-3. 
7 Benson DF, Gardner H, Meadows JC. Reduplicative paramnesia. Neurology (Minneap) 1976; 26:147-51.

8 Weinstein EA, Kahn RL. Denial of Illness: Symbolic and Psychological Aspects. Springfield: Charles C Thomas, 1955.

9 Weinstein EA. Reduplicative phenomena. In: Vinken PJ, Bruyn GN eds. Handbook of Clinical Neurology, Vol 3, Chap 9, New York: John Wiley \& Sons, $1969 ; 251-7$.

10 Weschler D. Manual for the Weschler Adult Intelligence Scale. New York: Psychological Corporation, 1955.

11 Russel EW. A multiple scoring method for the assessment of complex memory function. $J$ Consult Clin Psychol 1975; 43:800-9.

12 Benton AL. Revised Visual Retention Test: Manual. New York: Psychological Corporation, 1963.

13 Milner B. Effects of different brain lesions on card sorting. Arch Neurol 1963; 9:90-100.

14 Luria AR. Frontal lobe syndromes. In: Vinken PJ, Bruyn GN, eds. Handbook of Clinical Neurology, Vol 3, Chap 13. New York: John Wiley \& Sons, 1969; 229-50.

15 Paterson A, Zangwill OL. Disorders of visual space perception associated with lesions of the right cerebral hemisphere. Brain 1944; 67:331-58.

16 McFie J, Piercy MF, Zangwill OL. Visual-spatial agnosia. Brain 1950; 73:167-90.

17 Critchley M. The Parietal Lobes. London: Edward Arnold, 1953.

18 Newcombe F, Ritchie RW. Dissociated visual perception and spatial deficits in focal lesions of the right hemisphere. J Neurol Neurosurg Psychiatry 1969; 32:73-81.
19 Benton AL. Disorders of spatial orientation. In: Vinken PJ, Bruyn GN, eds. Handbook of Clinical Neurology, Vol 3, Chap 12. New York: John Wiley \& Sons, 1969; 212-28.

20 Arrigoni G, Derenti E. Constructional apraxia and hemispheric locus of lesion. Cortex 1964; 1:170-97.

21 Benton AL. Constructional apraxia the minor hemisphere. Confinia Neurol 1967; 27:1-17.

22 Warrington EK. Constructional apraxia. In: Vinken PJ, Bruyn GN, eds. Handbook of Clinical Neurology, Vol 4, Chap 4. New York: John Wiley \& Sons, 1969; 67-83.

23 Gilliat RW, Pratt RTC. Disorders of perception and performance in a case of right cerebral thrombosis. J Neurol Neurosurg Psychiatry 1952; 15:264-71.

24 Butters N, Barton M. Effect of parietal lobe damage on the performance of reversible operations in space. Neuropsychologia 1970; 8:205-14.

25 Ratcliff G, Newcombe F. Spatial orientation in man: effects of left, right and bilateral posterior cerebral lesions. J Neurol Neurosurg Psychiatry 1973; 36:448-54.

26 Gooddy W. Disorders of the time sense. In: Vinken PJ, Bruyn GN, eds. Handbook of Clinical Neurology, Vol 3, Chap 13. New York: John Wiley \& Sons, 1969; 229-50.

27 Plum F, Posner JB. The diagnosis of stupor and coma. In: Plum F, McDowell FH eds. Contemporary Neurology Series, vol 10. Philadelphia: FA Davis Co. 1972.

28 Posner JB. Consciousness and its disturbances. In: Beeson PB, McDermott W Wyngarden JB eds. Cecil Textbooks of Medicine, Chap 220 Philadelphia: WB Saunders Co, 1979. 